\title{
The Action of Chronic Nicotine on the Effects of Ethanol on Anxiety, Locomotion and Metabolism and the Feeding and Drinking Behaviors of Rats
}

\author{
Valentina Bashkatova*, Sergey Sudakov, Galina Nazarova, Elena Alexeeva \\ P.K. Anokhin Research Institute of Normal Physiology, Moscow, Russia \\ Email: v.bashkatova@nphys.ru
}

Received 27 August 2014; revised 26 September 2014; accepted 19 October 2014

Copyright @ 2014 by authors and Scientific Research Publishing Inc.

This work is licensed under the Creative Commons Attribution International License (CC BY). http://creativecommons.org/licenses/by/4.0/

(c) (i) Open Access

\begin{abstract}
The objective of these experiments was to study the effects of ethanol on the anxiety level, activity, metabolic rate, and feeding and drinking behaviors of rats that were chronically treated with nicotine. The chronic intake of nicotine changed the effects of the acute administration of ethanol. Thus, the nicotine-dependent rats demonstrated a significantly decreased anxiolytic-like effect in response to ethanol than did the control rats. This decrease may lead to a decrease in the sensitivity of animals to the positive reinforcing effects of ethanol and an increase in their consumption to achieve the desired effect. The negative action of ethanol on the metabolism, motor activity and drinking behavior of rats that chronically consumed nicotine was increased. Chronic nicotine intake can be assumed to lead to cross-tolerance of the effects of ethanol. On the contrary, the sensitivity to the action of ethanol increased.
\end{abstract}

\section{Keywords}

Nicotine, Ethanol, Metabolism, Drinking Behavior, Locomotion

\section{Introduction}

The joint use of nicotine and ethanol is widespread among humans. The episodic consumption of alcoholic beverages most often occurs against a background of chronic tobacco smoking [1]. Smoking tobacco is known to result in the action of nicotine on the nicotinic acetylcholine receptors in the brain. Receptors that are situated on

*Corresponding author.

How to cite this paper: Bashkatova, V., Sudakov, S., Nazarova, G. and Alexeeva, E. (2014) The Action of Chronic Nicotine on the Effects of Ethanol on Anxiety, Locomotion and Metabolism and the Feeding and Drinking Behaviors of Rats. Pharmacology \& Pharmacy, 5, 1077-1084. http://dx.doi.org/10.4236/pp.2014.511117 
dopamine-containing neurons in the mesocorticolimbic system are especially affected, which leads to an increased release of dopamine and produces various behavioral effects [2] [3]. The effects of ethanol on emotional and motivational processes also involve the release of dopamine in the extracellular space of the nucleus accumbens [4]. The chronic intake of nicotine induces changes in the density and affinity of acetylcholine receptors, which may change the effects of ethanol in such subjects [5] [6]. Chronic nicotine consumption was noted to lower the positive reinforcing effect of ethanol by suppressing ethanol-induced dopamine release in the nucleus accumbens [7] [8]. Chronic nicotine reduced the impact of ethanol on the locomotor activity of rats [6] [9], affected the NMDA current in the hippocampus [10] and decreased the heart rate and body temperature [11] [5]. Conversely, chronic nicotine administration increased the effect of ethanol on motor activity and dopamine turnover in the brain [12]. In addition, chronic nicotine intake increased ethanol self-administration behavior [13].

Ethanol and nicotine are known to significantly affect metabolic processes [14]-[16]. However, we did not find data that showed the mechanism by which ethanol affects the metabolism of animals that chronically receive nicotine.

Ethanol and nicotine cause positive reinforcing actions, which result in pleasant sensations. This effect includes anxiolytic effects. Unfortunately, we have not found data on the ethanol anxiolytic effect in animals that were chronically administered nicotine.

Ethanol and nicotine are well known to cause changes in feeding and drinking behaviors [15] [17] [18]. However, we have not discovered data on the effects of ethanol on the eating and drinking behaviors of animals that chronically consume nicotine.

Accordingly, the objective of these experiments was to study the effects of ethanol on the anxiety level, locomotor activity, metabolic rate and feeding and drinking behaviors of rats that were chronically treated with nicotine.

\section{Materials and Methods}

The experiments were performed on 32 male Wistar rats obtained from the Stolbovaja nursery (Russian Academy of Medical Sciences). The animals (basal weight 240 - 270 g) were housed in individually ventilated cages (4 rats per cage) under a 12:12-h light-dark cycle with free access to food and water. The experiment was conducted in accordance with the "Rules of Studies on Experimental Animals" (approved by the Ethics Committee of the P. K. Anokhin Institute of Normal Physiology; protocol No. 1, 3.09.2005), the requirements of the World Society for the Protection of Animals (WSPA) and the European Convention for the Protection of Experimental Animals.

All rats were divided into 4 groups ( 8 animals per group). Two groups of animals were subcutaneously (sc) treated twice per day with nicotine at dose of $2 \mathrm{mg} / \mathrm{kg}$ for 7 days, followed by $3 \mathrm{mg} / \mathrm{kg}$ nicotine for the next 14 days. Determination of PH values of nicotine solutions was measured using Orion Research digital ionalyzer/ $501 \mathrm{Ph}$. The PH values of studied nicotine solutions ( $2 \mathrm{mg} / \mathrm{kg}$ or $3 \mathrm{mg} / \mathrm{kg}$ ) were 3.45 - 3.50 in depend on concentration. Nicotine at dose $2 \mathrm{mg} / \mathrm{kg}$ or $3 \mathrm{mg} / \mathrm{kg}$ was injected to rats subcutaneously and the irritations after injections were not observed. The animals in the other two groups received equivalent amounts of sc saline twice per day for 21 days. On the day of the behavior experiment, the animals in group 1 (control, pretreated with saline for 21 days) received sc saline and a second dose of gastrically administered saline after 5 minutes. Group 2 (pretreated with nicotine for 21 days) received nicotine ( $3 \mathrm{mg} / \mathrm{kg}$, sc) and a dose of gastrically administered saline after 5 minutes. Group 3 (pretreated with saline for 21 days) received saline and a $40 \%$ solution of ethanol ( $6 \mathrm{~g} / \mathrm{kg}$ intragastrically) after 5 minutes. Group 4 (pretreated with nicotine for 21 days) received nicotine 3 $\mathrm{mg} / \mathrm{kg}$, sc) and a $40 \%$ solution ethanol (6 g/kg intragastrically) after 5 minutes. After 60 minutes, the rats were placed in an elevated plus maze (EPM, Columbus, USA) for 5 minutes, which recorded the time spent in the center, in the open arms and closed arms, the motor activity in different parts of the EPM and the duration of grooming [19]. Immediately thereafter, the animals were placed into the standard "home" cages designed by Phenomaster systems (TSE Instruments, Germany) for 24 hours. The metabolic rate was determined using indirect calorimetry, locomotor activity, water and food consumption, which we registered for every Phenomaster cage for 24 hours at intervals of 60 minutes.

The data obtained were subjected to statistical and analytical processing. A normal distribution was assumed for the data to derive indicators to evaluate statistically significant differences between the parameters obtained from experimental and control animals using ANOVA. 


\section{Results}

Our study showed that the chronic administration of nicotine for 3 weeks did not significantly affect the level of anxiety. The time spent on the open arms of the EPM and locomotor activity in the open arms of the EPM was not significantly different between the animals treated with nicotine and the control group treated with saline. Nevertheless, the activity in other parts of the EPM was increased compared to the control (Table 1). During the first 8 hours after the administration of nicotine (light phase of the day), the rats did not demonstrate a significant effect on locomotor activity, metabolism, food and water intake, or the intensity of the movement in the cage center compared with the control animals. However, these animals showed decreased locomotor activity, inhibited drinking and eating and reduced activity in the center of the cage $8 \mathrm{~h}$ aver the last injection of nicotine, which coincided with the onset of the dark phase. These changes were observed after the end of the dark phase and persisted until the end of the experiment (Figures 1-5).

Table 1. The effect of nicotine and ethanol on the anxiety-like behavior of rats tested in the EPM.

\begin{tabular}{cccc}
\hline & $\begin{array}{c}\text { Time spent on the open arms } \\
\text { (c) }\end{array}$ & $\begin{array}{c}\text { Activity on the open arms } \\
\text { (relative units) }\end{array}$ & $\begin{array}{c}\text { Activity on the close arms } \\
\text { (relative units) }\end{array}$ \\
\hline S-S & $5.1 \pm 2.7$ & $0.63 \pm 0.15$ & $1.87 \pm 0.39$ \\
S-E & $65.5 \pm 12.9^{*}$ & $2.88 \pm 0.67^{*}$ & $3.62 \pm 0.57^{*}$ \\
N-S & $10.0 \pm 2.2^{*}$ & $1.13 \pm 0.47$ & $3.75 \pm 0.73^{*}$ \\
N-E & $17.2 \pm 4.1^{* \#}$ & $1.88 \pm 0.72^{*}$ & $2.87 \pm 0.65^{*}$ \\
\hline
\end{tabular}

S-S: control group (rats chronically with saline and then once on the experiment day); S-E: a group of rats chronically treated with saline and one dose of ethanol on the experiment day; N-S: a group of rats that were chronically administered nicotine and one dose of saline on the experiment day; N-E: a group of rats chronically administered nicotine and one dose of ethanol on the experiment day; ${ }^{*} \mathrm{P}<0.05$ compared to the group S-S; ${ }^{\#} \mathrm{P}<0.05$ compared to the group of S-E.

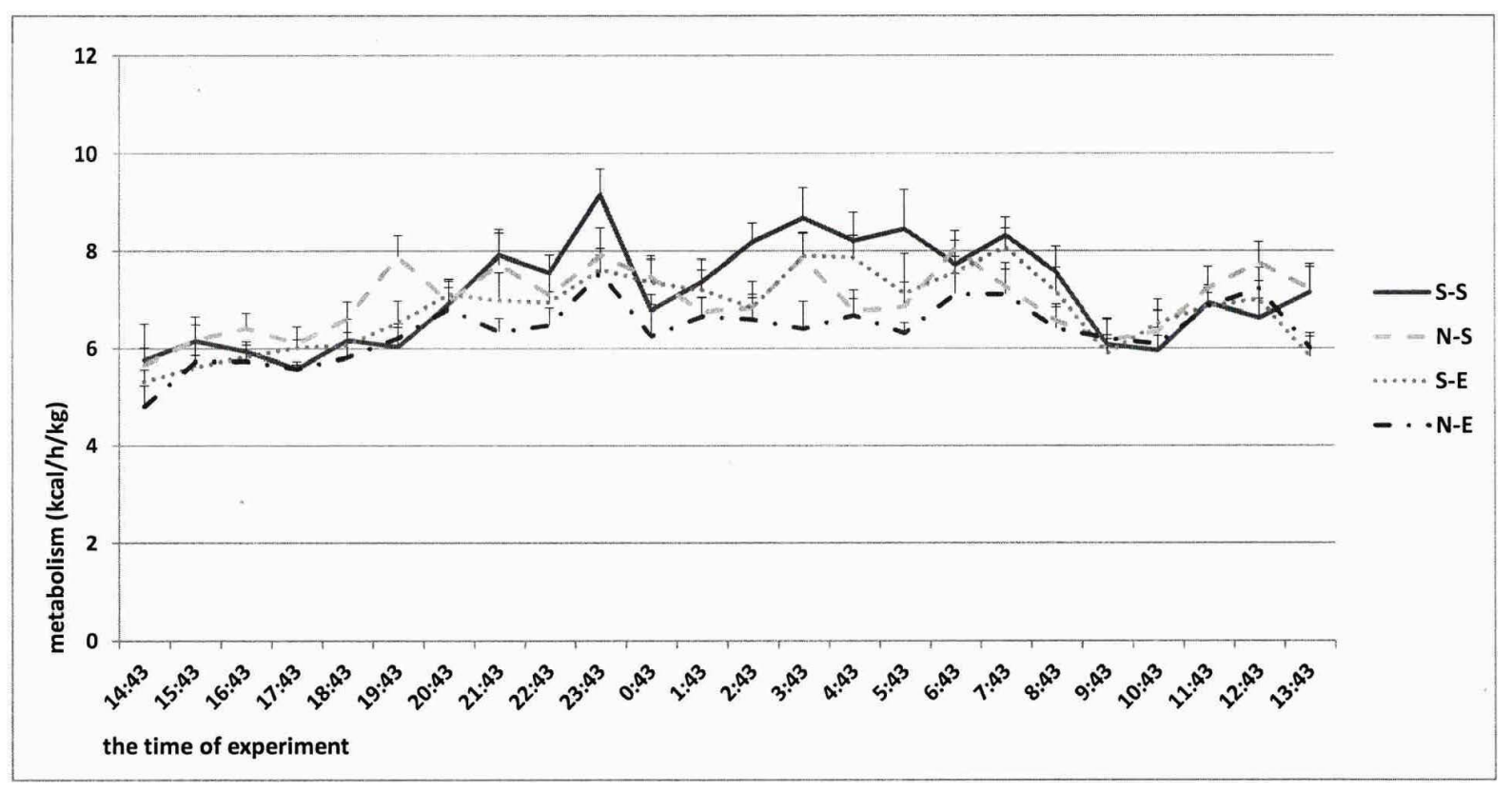

Figure 1. Effect of chronic nicotine on ethanol effects on dynamics of metabolism level (kcal/h/ $/ \mathrm{kg})$. S-S: control grouprats treated with saline chronically (21 day) and then saline once in experimental day. N-S: a group of rats that chronically administered nicotine (2 mg/kg subcutaneously (sc), twice per day, for 7 days, followed for next 14 days-nicotine $3 \mathrm{mg} / \mathrm{kg}$ ) and once saline in experimental day. S-E: a group of rats chronically treated with saline during 21 days and once $40 \%$ solution ethanol (6 g/kg intragastrically) in experimental day. N-E: a group of rats chronically administered nicotine $(2 \mathrm{mg} / \mathrm{kg}$ subcutaneously (sc), twice per day, for 7 days, followed for next 14 days-nicotine $3 \mathrm{mg} / \mathrm{kg}$ ) and once $40 \%$ solution ethanol ( $6 \mathrm{~g} / \mathrm{kg}$ intragastrically) in experimental day. On the horizontal axis: the time of the experiment (dark period from 20:00 to 08:00). For measurement of metabolism level the animals were placed into the standard cages of "Phenomaster system" for 24 hours. The metabolic rate determined using indirect calorimetry. Ethanol injected to nicotine-addicted rats decreased metabolic rate activity followed $7 \mathrm{~h}$ after administration of ethanol (which coincides with the beginning of the dark phase). 


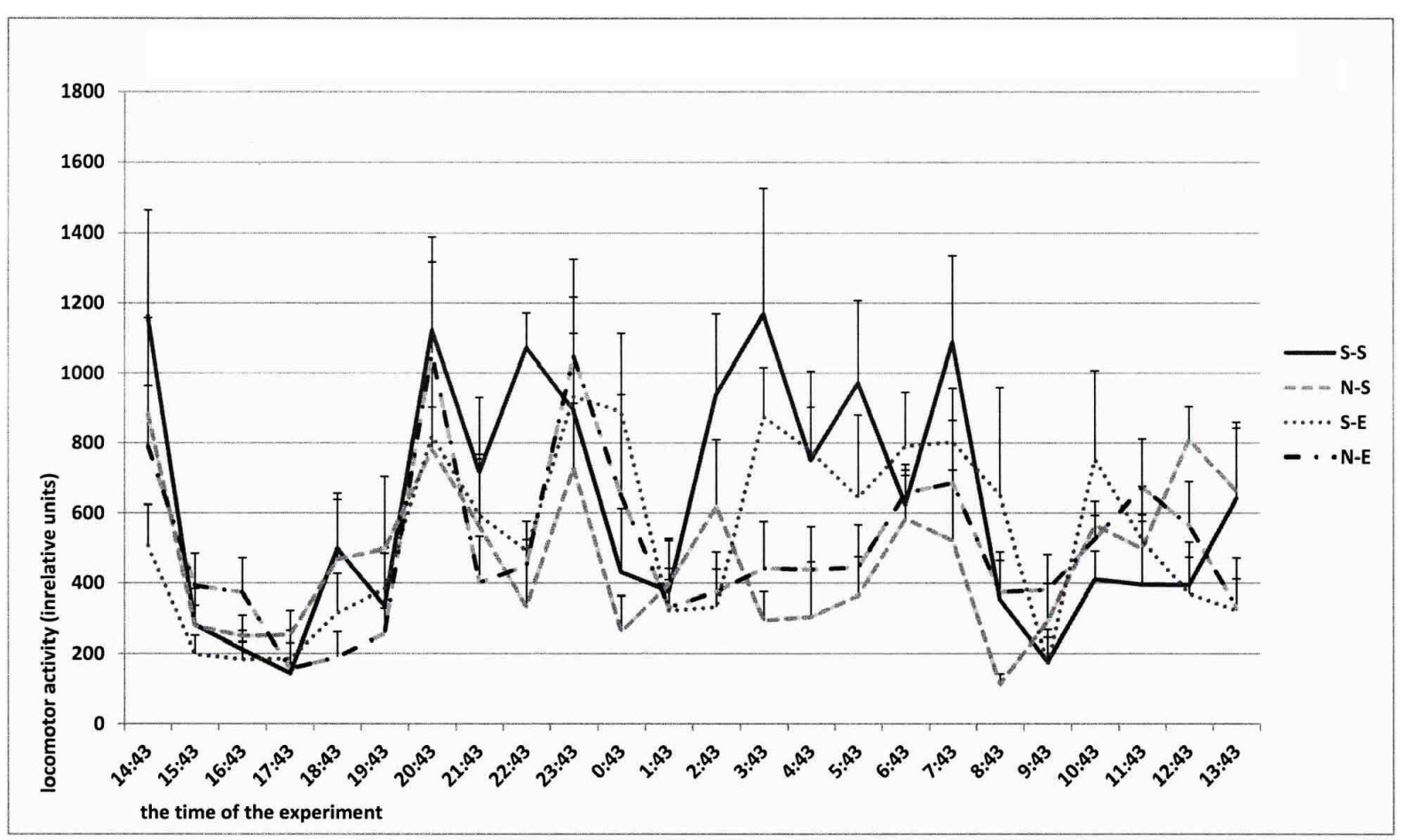

Figure 2. Effect of chronic nicotine on ethanol effects on dynamics of locomotor activity (in relative units). The other legends (groups of animals were) the same as in Figure 1. On the horizontal axis-the time of the experiment (dark period from 20:00 to 08:00). For measurement of dynamics of locomotor activity were placed into the standard cages of "Phenomaster system" for 24 hours. Ethanol injected to nicotine-treated rats produced decrease of locomotor activity with the beginning of the dark phase (5 - $7 \mathrm{~h}$ after administration of ethanol.

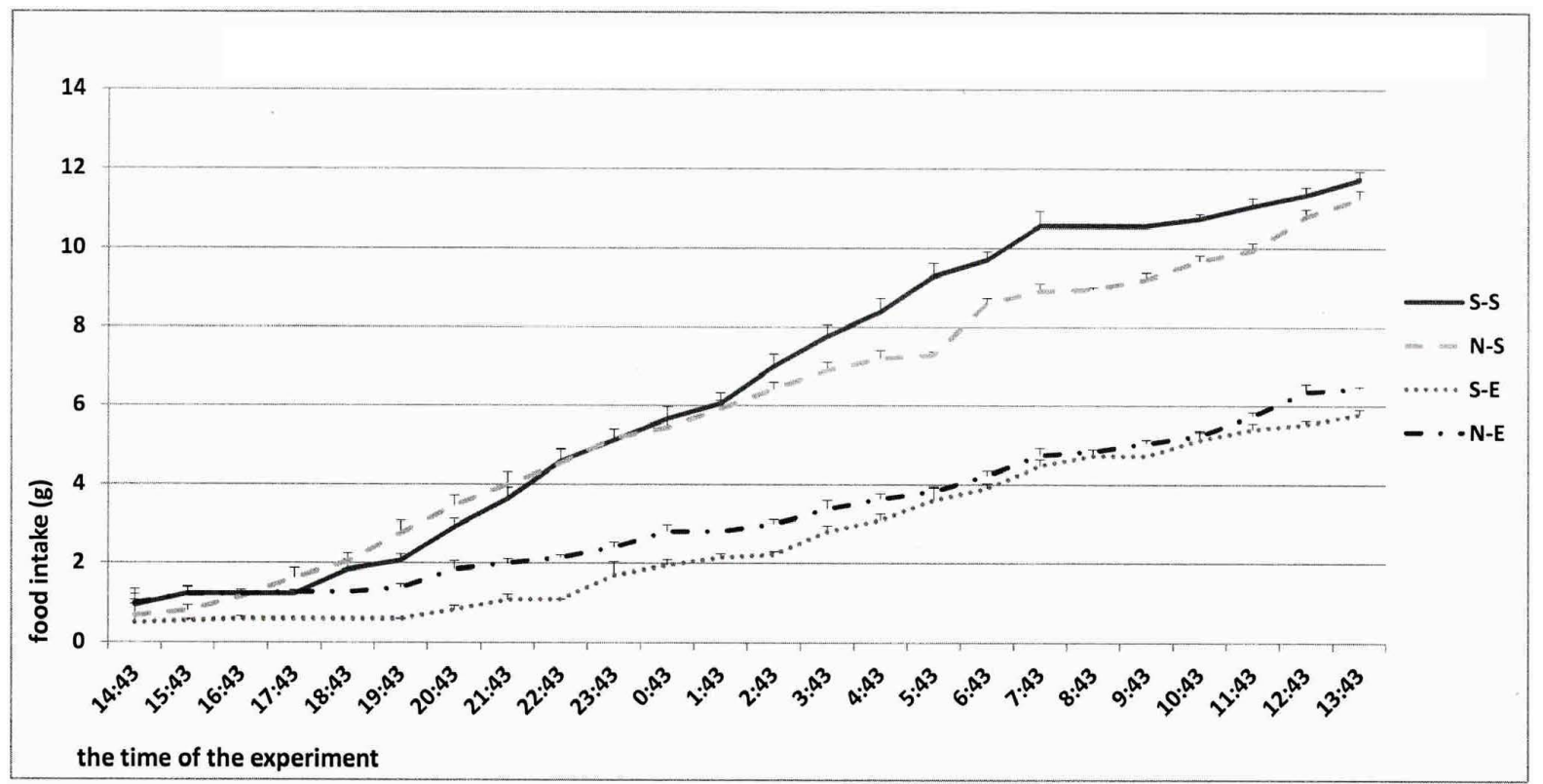

Figure 3. Effect of chronic nicotine on ethanol effects on dynamics of food intake (grams). The other legends (groups of animals were) the same as in Figure 1. On the horizontal axis - the time of the experiment (dark period from 20:00 to 08:00). On the ordinate axis-cumulative curve, where each value is added to the previous one. For measurement of dynamics of locomotor activity were placed into the standard cages of "Phenomaster system" for 24 hours. A suppression of feeding behavior was observed within 12 - 14 hours after administration of ethanol to nicotine treated rats as well as in saline treated animals. 


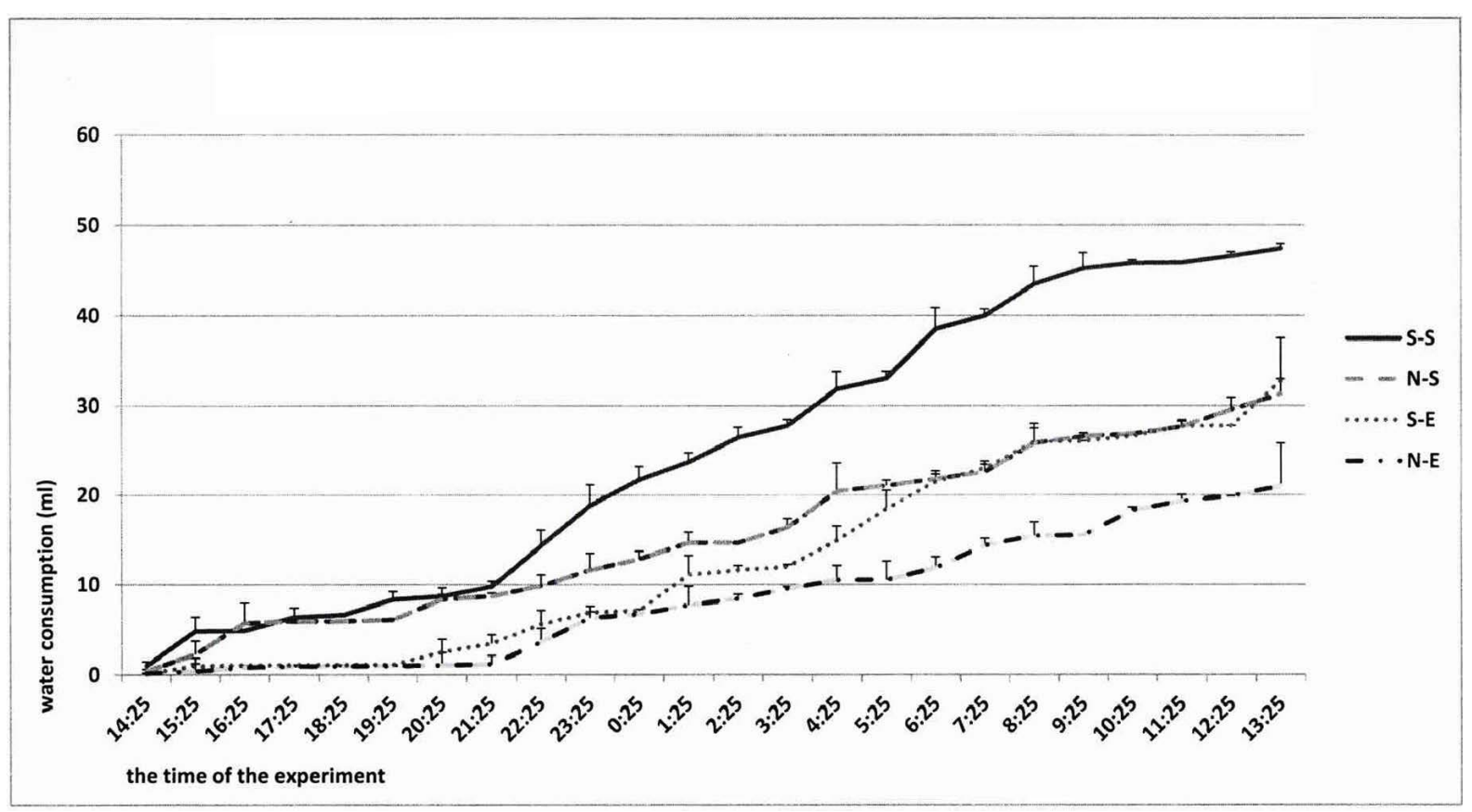

Figure 4. Effect of chronic nicotine on ethanol effects on dynamics of water consumption (ml). The other legends (groups of animals were) the same as in Figure 1. On the horizontal axis-the time of the experiment (dark period from 20:00 to 08:00). On the ordinate axis - cumulative curve, where each value is added to the previous one. For measurement of dynamics of locomotor activity were placed into the standard cages of "Phenomaster system" for 24 hours. Rats which received ethanol $13 \mathrm{~h}$ before placing them in the cages "Phenomaster" drank 2.5 times less than the control animals. For the rest time the water and food intake of these rats was also reduced.

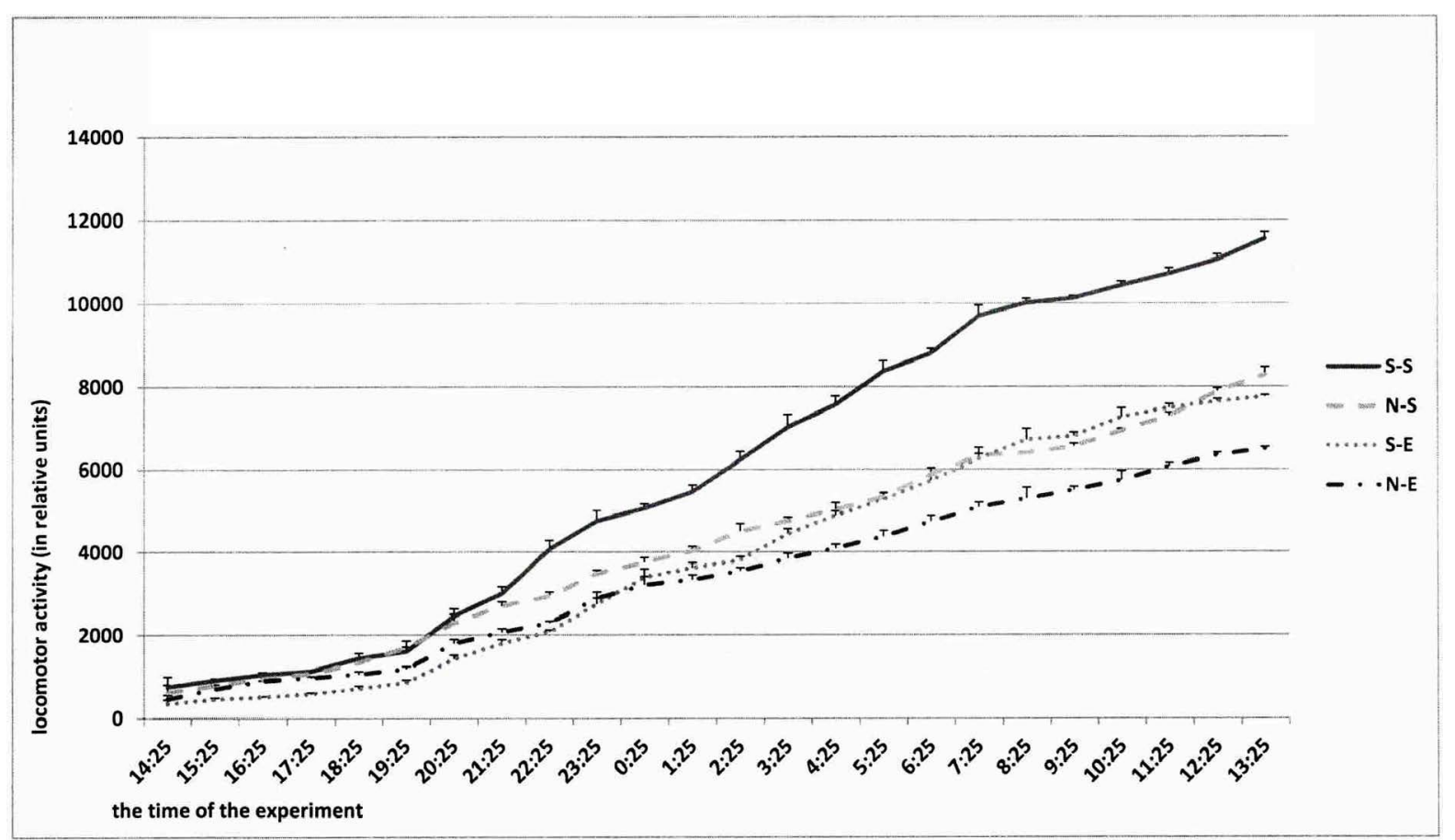

Figure 5. Effect of chronic nicotine on ethanol effects on dynamics of locomotor activity in the cage center (relative units) of the different experimental groups of rats. The other legends (groups of animals were) the same as in Figure 1. On the horizontal axis - the time of the experiment (dark period from 20:00 to 08:00). Animals received ethanol as compared with the control, significantly reduced motor activity in the center of cages "Phenomaster" during all the observation time (24 h). 
The animals treated with chronic saline1 h after the intragastric administration of ethanol manifested a significant increase in the time spent in the open arms of the EPM. In addition, an increase in the motor activity in all parts of the EPM was also observed (Table 1). We did not find any significant changes in the level of metabolism or the locomotor activity in the center of the cage for $24 \mathrm{~h}$ after a single injection of ethanol (Figure 1, Figure 2). However, the eating and drinking behavior of the rats was significantly suppressed within 12 - 14 hours after ethanol administration. Rats that received ethanol $13 \mathrm{~h}$ before placing them in Phenomaster home cages ate in 3 times and drank 2.5 times less than the control animals. The water and food intake of these rats was also reduced during the rest time. The daily water intake of control animals was $47 \pm 6.2 \mathrm{ml}$, while that of the animals treated with ethanol was $32.7 \pm 5.8 \mathrm{ml}$. Control rats ate $11.7 \pm 1.9 \mathrm{~g}$ for $24 \mathrm{~h}$, and the animals treated with ethanol ate $5.7 \pm 1.2 \mathrm{~g}$ (Figure 3 and Figure 4). Animals that received ethanol showed significantly reduced motor activity in the center Phenomaster cages compared to the control during the entire observation time (24 h) (Figure 5).

The administration of the ethanol to animals chronically treated with nicotine led to a significantly reduced anxiolytic effect compared to the saline treated rats. The animals treated with ethanol demonstrated an almost 4-fold decrease in the time spent in the open arms of the EPM (Table 1). Ethanol injected into nicotine-addicted rats decreased the metabolic rate and locomotor activity $7 \mathrm{~h}$ after the administration of ethanol (which coincides with the beginning of the dark phase). A suppression of feeding and drinking behavior was observed within 12 14 hours after the administration of ethanol to nicotine-treated rats and saline-treated animals. Moreover, the inhibition of the drinking behavior of nicotine-dependent rats was more pronounced. The daily intake of water by nicotine-treated rats after ethanol administration was $20.97 \pm 4.5 \mathrm{ml}$.

\section{Discussion}

The data indicate that the chronic intake of nicotine in rats does not change the registered physiological parameters, except for the psychostimulant-like effect, which was observed just after each regular injection of nicotine. On the contrary, a suppression of eating and drinking behavior was established $8 \mathrm{~h}$ after the injection of nicotine. Although the appearance of these indicated effects coincided with the onset of the dark phase of the day, these effects were connected to the waning of nicotine influence, which leads to withdrawal syndrome in nicotinedependent animals.

Nicotine has been shown to affect anxiety and depression in both human and animal studies [20]-[22]. The data suggest that nicotinic acetylcholine receptors (nAChRs) can modulate the function of pathways involved in the stress response, anxiety and depression in the normal brain and that smoking can result in changes in the anxiety level and mood [23] [24]. However, the effects of nicotine are complex, and nicotine treatment can be either anxiolytic or anxiogenic depending on the anxiety model tested, the route of nicotine administration and the time course of administration. The paradoxical effects of nicotine on emotion are likely due to the broad expression of nAChRs throughout the brain, the large number of nAChR subtypes that have been identified and the ability of nicotine treatment to both activate and desensitize nAChRs [25]. A single injection of nicotine (0.1 $0.5 \mathrm{mg} / \mathrm{kg}$ s.c.) reportedly decreased the percentage of time spent on the open arms of EPM, while nicotine injected for 7 days at the same dose increased this parameter, i.e., produced an anxiolytic effect [20]. The individual sensitivity of animals is also very important for the anxiolitic/anxiogenic action of nicotine. Thus, nicotine was shown to act as an anxiolytic agent in transgenic mice that constitutively overexpressed AChE-R. This effect was not observed in wild type control mice [26].

Chronic treatment with nicotine alters the effects of the acute administration of ethanol. Thus, the administration of ethanol to nicotine-dependent rats, produced a significant increase of time spent in the open arms of the EPM than that of saline treated rats. However, the psychostimulant effect of ethanol was maintained. Thus, the chronic intake of nicotine may lead to selective cross-tolerance to the action of ethanol, which correlates with results of other studies [10] [27]. Nicotine-dependent animals showed a more pronounced response to the administration of ethanol when no longer under the influence of nicotine. Thus, they experienced a more significant depressive-like effect. This effect was accompanied by a more pronounced suppression of drinking behavior and anxiogenic effects as well as a suppressed metabolism, which was not observed in saline-treated rats. Nicotine pretreatment was shown to significantly enhance the ethanol-induced locomotor stimulation and elevation of dihydroxyphenylacetic acid/dopamine quotient in the brain [12]. These results suggest that neuronal mechanisms related to the locomotor stimulatory effects of ethanol may be sensitized by pre-exposure to nicotine. 
Chronic nicotine treatment also produced cross-tolerance to the effects of ethanol on glutamatergic activity, which led to a potential increase in the use of these products [10].

\section{Conclusion}

In summary, the chronic administration of nicotine suppressed the sensitivity of animals to the anxiolytic effect of ethanol. This fact may stipulate a reduction of rat sensitivity to the positively reinforced, euphoric effect of ethanol and the increase of ethanol consumption in order to achieve the desired effect. In this case, the negative effect of ethanol on the metabolism, locomotor activity and drinking behavior in rats treated with nicotine chronically was exacerbated. It might be concluded that more studies including detailed monitoring of many physiological parameters are needed to draw attention to the gaps in our knowledge of combined administration of nicotine with alcohol and argues that neuroscience and clinical research efforts need to be combined with health policy options to reduce the harm associated with nicotine and alcohol abuse.

\section{References}

[1] Miller, N.S. and Gold, M.S. (1998) Comorbid Cigarette and Alcohol Addiction: Epidemiology and Treatment. Journal of Addictive Diseases, 17, 55-66. http://dx.doi.org/10.1300/J069v17n01_06

[2] Alburges, M.E., Hoonakker, A.J. and Hanson, G.R. (2007) Nicotinic and Dopamine D2 Receptors Mediate Nicotine-Induced Changes in Ventral Tegmental Area Neurotensin System. European Journal of Pharmacology, 573, 124132. http://dx.doi.org/10.1016/j.ejphar.2007.06.063

[3] Novak, G., Seeman, P. and Le Foll, B. (2010) Exposure to Nicotine Produces an Increase in Dopamine D2 (High) Receptors: A Possible Mechanism for Dopamine Hypersensitivity. International Journal of Neuroscience, 120, 691-697. http://dx.doi.org/10.3109/00207454.2010.513462

[4] Schier, C.J., Dilly, G.A. and Gonzales, R.A. (2013) Intravenous Ethanol Increases Extracellular Dopamine in the Medial Prefrontal Cortex of the Long-Evans rat. Alcoholism: Clinical and Experimental Research, 37, 740-747. http://dx.doi.org/10.1111/acer.12042

[5] Collins, A.C., Burch, J.B., de Fiebre, C.M. and Marks, M.J. (1988) Tolerance to and Cross Tolerance between Ethanol and Nicotine. Pharmacology, Biochemistry and Behavior, 29, 365-373. http://dx.doi.org/10.1016/0091-3057(88)90170-0

[6] Collins, A.C., Wilkins, L.H., Slobe, B.S., Cao, J.Z. and Bullock, A.E. (1996) Long-Term Ethanol and Nicotine Treatment Elicit Tolerance to Ethanol. Alcoholism: Clinical and Experimental Research, 6, 990-999. http://dx.doi.org/10.1111/j.1530-0277.1996.tb01936.x

[7] López-Moreno, J.A., Scherma, M., Rodríguez de Fonseca, F., González-Cuevas, G., Fratta, W. and Navarro, M. (2008) Changed Accumbal Responsiveness to Alcohol in Rats Pre-Treated with Nicotine or the Cannabinoid Receptor Agonist WIN 55,212-2. Neuroscience Letters, 433, 1-5. http://dx.doi.org/10.1016/j.neulet.2007.11.074

[8] Söderpalm, B., Ericson, M., Olausson, P., Blomqvist, O. and Engel, J.A. (2000) Nicotinic Mechanisms Involved in the Dopamine Activating and Reinforcing Properties of Ethanol. Behavioural Brain Research, 113, 85-96. http://dx.doi.org/10.1016/S0166-4328(00)00203-5

[9] Lallemand, F., Ward, R.J. and De Witte, P. (2009) The Influence of Chronic Nicotine Administration on Behavioral and Neurochemical Parameters of Male and Female Rats after Repeated Binge Drinking Exposure. Alcohol Alcoholism, 44, 535-546. http://dx.doi.org/10.1093/alcalc/agp047

[10] Proctor, W.R., Dobelis, P., Moritz, A.T. and Wu, P.H. (2011) Chronic Nicotine Treatment Differentially Modifies acute Nicotine and Alcoholactions on GABA(A) and Glutamate Receptors in Hippocampal Brain Slices. British Journal of Pharmacology, 162, 1351-1363. http://dx.doi.org/10.1111/j.1476-5381.2010.01141.x

[11] Burch, J.B., de Fiebre, C.M., Marks, M.J. and Collins, A.C. (1988) Chronic Ethanol or Nicotine Treatment Results in Partial Cross-Tolerance between These Agents. Psychopharmacology, 95, 452-458. http://dx.doi.org/10.1007/BF00172954

[12] Johnson, D.H., Blomqvist, O., Engel, J.A. and Söderpalm, B. (1995) Subchronic Intermittent Nicotine Treatment Enhances Ethanol-Induced Locomotor Stimulation and Dopamine Turnover in Mice. Behavioural Pharmacology, 6, 203-207. http://dx.doi.org/10.1097/00008877-199503000-00013

[13] Clark, A., Lindgren, S., Brooks, S.P., Watson, W.P. and Little, H.J. (2001) Chronic Infusion of Nicotine Can Increase Operant Self-Administration of Alcohol. Neuropharmacology, 41, 108-117. http://dx.doi.org/10.1016/S0028-3908(01)00037-5

[14] Leow, Y.H. and Maibach, H.I. (1998) Cigarette Smoking, Cutaneous Vasculature, and Tissue Oxygen. Clinics in 
Dermatology, 16, 579-584. http://dx.doi.org/10.1016/S0738-081X(98)00042-X

[15] Levin, E.D., Morgan, M.M., Galvez, C. and Ellison, G.D. (1987) Chronic Nicotine and Withdrawal Effects on Body Weight and Food and Water Consumption in Female Rats. Physiology \& Behavior, 39, 441-444. http://dx.doi.org/10.1016/0031-9384(87)90370-2

[16] Taylor, B.E., Brundage, C.M. and McLane, L.H. (2013) Chronic Nicotine and Ethanol Exposure Both Disrupt Central Ventilatory Responses to Hypoxia in Bullfrog Tadpoles. Respiratory Physiology \& Neurobiology, 187, $234-243$. http://dx.doi.org/10.1016/j.resp.2013.04.004

[17] Essig, C.F. (1968) Increased Water Consumption Following Forced Drinking of Alcohol in Rats. Psychopharmacologia, 12, 333-337. http://dx.doi.org/10.1007/BF00401411

[18] Wager-Srdar, S.A., Levine, A.S., Morley, J.E., Hoidal, J.R. and Niewoehner, D.E. (1984) Effects of Cigarette Smoke and Nicotine on Feeding and Energy. Physiology \& Behavior, 32, 389-395. http://dx.doi.org/10.1016/0031-9384(84)90252-X

[19] Pellow, S., Chopin, P., File, S.E. and Briley, M. (1985) Validation of Open: Closed Arm Entries in an Elevated Plus-Maze as a Measure of Anxiety in the Rat. Journal of Neuroscience Methods, 14, 149-167. http://dx.doi.org/10.1016/0165-0270(85)90031-7

[20] Biala, G. and Budzynska, B. (2006) Effects of Acute and Chronic Nicotine on Elevated Plus Maze in Mice: Involvement of Calcium Channel. Life Sciences, 79, 81-88. http://dx.doi.org/10.1016/j.lfs.2005.12.043

[21] Tizabi, Y., Hauser, S.R., Tyler, K.Y., Getachew, B., Madani, R., Sharma, Y. and Manaye, K.F. (2010) Effects of Nicotine on Depressive-Like Behavior and Hippocampal Volume of Female WKY Rats. Progress in Neuro-Psychopharmacology and Biological Psychiatry, 34, 62-69. http://dx.doi.org/10.1016/j.pnpbp.2009.09.024

[22] Turner, J.R., Castellano, L.M. and Blendy, J.A. (2011) Parallel Anxiolytic-Like Effects and Upregulation of Neuronal Nicotinic Acetylcholine Receptors Following Chronic Nicotine and Varenicline. Nicotine \& Tobacco Research, 13, 41-46. http://dx.doi.org/10.1093/ntr/ntq206

[23] Gotti, C., Clementi, F., Fornari, A., Gaimarri, A., Guiducci, S., Manfredi, I., Moretti, M., Pedrazzi, P., Pucci, L. and Zoli, M. (2009) Structural and Functional Diversity of Native Brain Neuronal Nicotinic Receptors. Biochemical Pharmacology, 78, 703-711. http://dx.doi.org/10.1016/j.bcp.2009.05.024

[24] Sajja, R.K. and Rahman, S. (2012) Neuronal Nicotinic Receptor Ligands Modulate Chronic Nicotine-Induced Ethanol Consumption in C57BL/6J Mice. Pharmacology Biochemistry and Behavior, 102, 36-43. http://dx.doi.org/10.1016/j.pbb.2012.03.017

[25] Picciotto, M.R., Brunzell, D.H. and Caldarone, B.J. (2002) Effect of Nicotine and Nicotinic Receptors on Anxiety and Depression. Neuroreport, 13, 1097-1106. http://dx.doi.org/10.1097/00001756-200207020-00006

[26] Salas, R., Main, A., Gangitano, D.A., Zimmerman, G., Ben-Ari, S., Soreq, H. and De Biasi, M. (2008) Nicotine Relieves Anxiogenic-Like Behavior in Mice that Overexpress the Read-Through Variant of Acetylcholinesterase but Not in Wild-Type Mice. Molecular Pharmacology, 74, 1641-1648. http://dx.doi.org/10.1124/mol.108.048454

[27] Gulick, D. and Gould, T.J. (2008) Interactive Effects of Ethanol and Nicotine on Learning in C57BL/6J Mice Depend on both Dose and Duration of Treatment. Psychopharmacology, 196, 483-495. http://dx.doi.org/10.1007/s00213-007-0982-x 
Scientific Research Publishing (SCIRP) is one of the largest Open Access journal publishers. It is currently publishing more than 200 open access, online, peer-reviewed journals covering a wide range of academic disciplines. SCIRP serves the worldwide academic communities and contributes to the progress and application of science with its publication.

Other selected journals from SCIRP are listed as below. Submit your manuscript to us via either submit@scirp.org or Online Submission Portal.
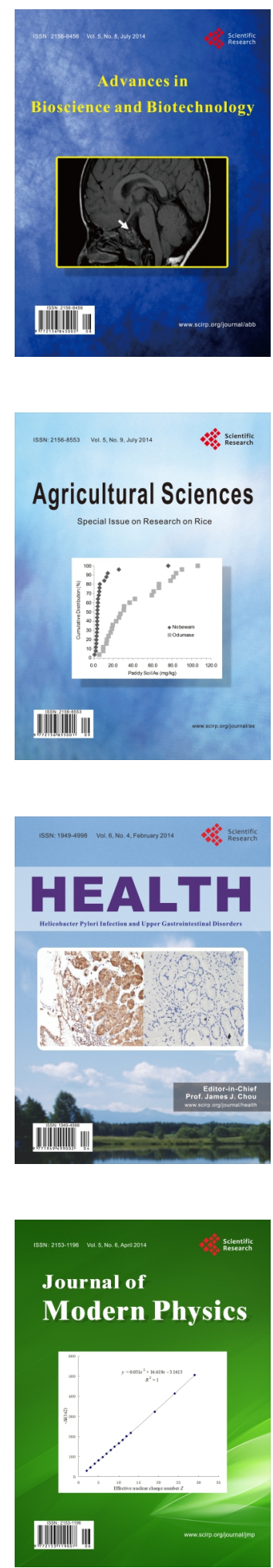
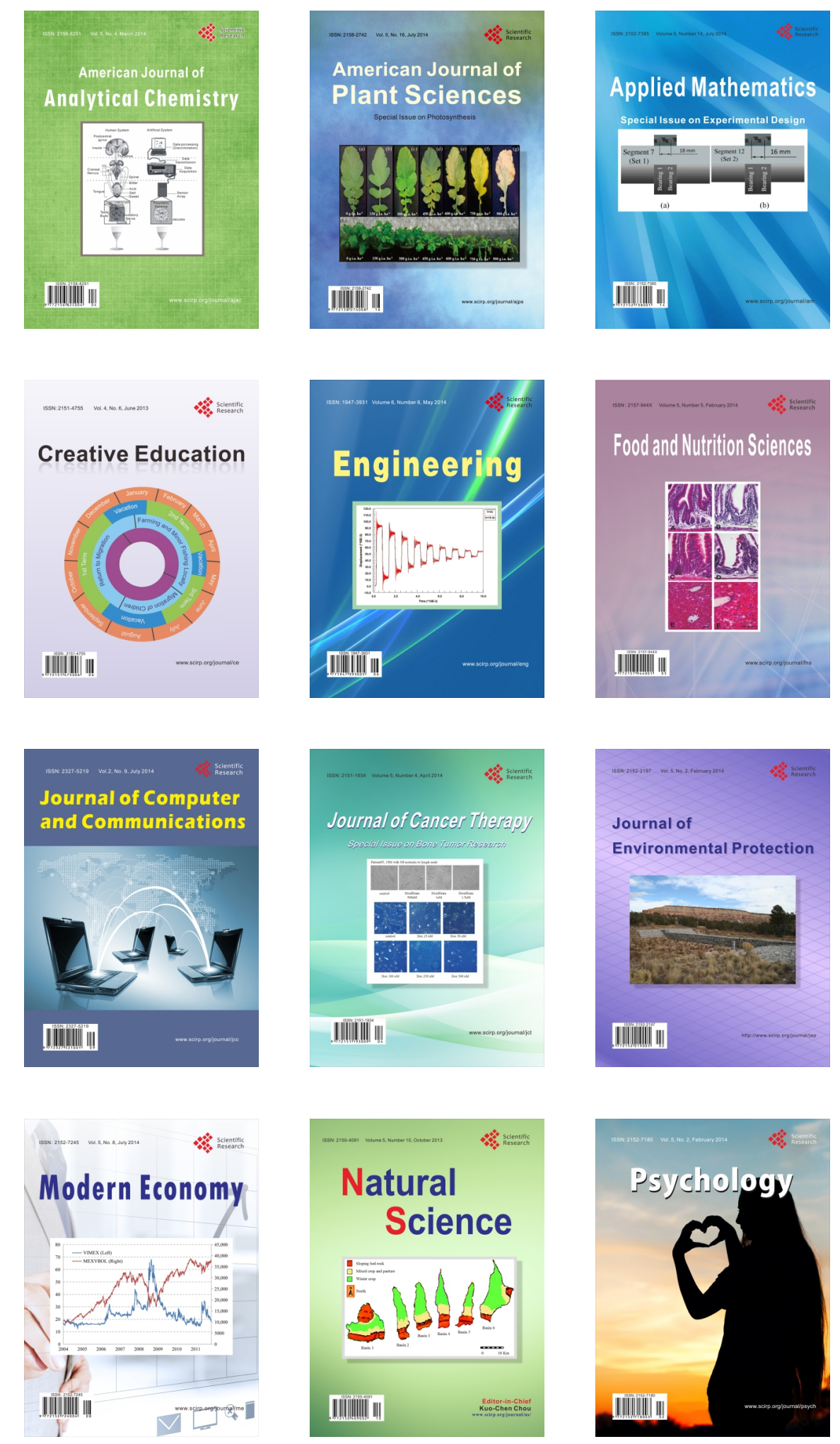